\title{
El monstruo: Lo otro del Hombre. Un abordaje arqueológico de la monstruosidad en Hesíodo
}

\author{
María Cecilia Colombani \\ Universidad de Morón \\ Universidad Nacional de Mar del Plata \\ mcolombani@unimoron.edu.ar
}

RESUMO

O objetivo do presente artigo consiste em pensar a figura do monstro no âmbito geral do universo mítico grego, como modo de tensionar a dicotomia Mesmidade e Alteridade.

PALAVRAS-CHAVE: Mesmidade; Alteridade; monstro; Hesíodo; Foucault.

No se puede concebir ni definir el Mismo sino en relación con el Otro, con la multiplicidad de otros. Si el Mismo permanece encerrado en sí mismo, no puede haber pensamiento. Ni civilización. ${ }^{1}$

\section{Introducción}

El proyecto del presente artigo consiste en pensar la figura del monstruo en el marco general del universo mítico griego, como modo de tensionar la díada Mismidad y Otredad.

El proyecto consiste en ensayar una mirada arqueológica sobre el tema de la monstruosidad en Teogonía. La arqueología foucaultiana ${ }^{2}$ ha de marcarnos el rumbo y la dirección del trabajo. La monstruosidad, leída desde un abordaje arqueológico, visibiliza diferentes capas a lo largo de distintas configuraciones epocales que van constituyendo una cierta espesura de saber y de discurso en torno al objeto recortado.

El presente trabajo intenta rastrear la prehistoria de la monstruosidad, excavando la superposición de capas que a lo largo de la historia han constituido la experiencia de lo monstruoso.

Se trata, en última instancia, de proponer un abordaje arqueológico que permita recorrer los distintos pliegues que han configurado un cierto conglomerado que se inscribe en el marco de la Otredad como experiencia extrema.

La monstruosidad arrastra tras de sí una espesura que constituye precisamente su prehistoria. Recorrer esa espesura es recorrer las capas de su formación como tal.

\footnotetext{
${ }^{1}$ Cf. Vernant, J. P. La muerte en los ojos. Gedisa, 1983, p. 38.

${ }^{2}$ Esta introducción y el marco teórico general que anima el presente trabajo se inscribe en el pensamiento de Michel Foucault y en los conceptos propios del llamado período arqueológico, situado en la década del 60 y plasmados, sobre todo en sus textos Las Palabras y las Cosas y la Arqueología del Saber.
} 
En ese sentido, la visión arqueológica de la monstruosidad implica situarse en los pliegues de la historia como universo simbólico de representaciones.

El modo habitual de situarse en un objeto-problema desde el horizonte arqueológico consiste en instalarse en una cierta representación, que opera desde la superficie y desde allí, desde una relativa "cuestión presente" remontarse a esas capaspliegues que marcan el conglomerado.

Fue precisamente el texto de Michel Foucault Los anormales, de reciente aparición, el que nos impulsó a trazar un arco de lectura entre esa "cuestión presente", que no denota una cuestión temporal, sino, más bien, una lectura de sedimentación de representaciones culturales, y el universo mítico, con el objeto de excavar las capas más profundas de un conglomerado que no puede prescindir del discurso mítico para dar cuenta de su composición.

Es allí, revolviendo esos bajos fondos, donde se encuentra las figuras monstruosas que devuelve Teogonía como relato fundacional. El tópos mítico devuelve esas figuras que parecen reunir las características que las representaciones ulteriores han adscrito al monstruo como forma de lo otro.

El trabajo ha de moverse, entonces, entre dos horizontes. El primero, de neto corte antropológico, desplegará un análisis de la dimensión de la monstruosidad, para, en un segundo momento-horizonte, salir al cruce de las figuras monstruosas y buscar las líneas de parentesco con el primer apartado.

\section{El imaginario simbólico ${ }^{3}$}

Indudablemente, el monstruo representa un hito en la historia de la transgresión. Es esta una noción capital para abordar la problemática de la monstruosidad, ensayando una "arqueología de la anormalidad".

En el presente trabajo nos proponemos abordar el extremo mismo de la noción de normalidad y medida. Nos referimos al "monstruo" para ver su ubicación en el marco general de las representaciones sociales.

Antes de introducirnos de lleno en el tópos de la monstruosidad, optaremos por algunas consideraciones antropológicas en torno al imaginario de los anormales, para ver en qué medida la figura del monstruo se solidariza con esa familia.

\footnotetext{
${ }^{3}$ El presente apartado sigue las consideraciones de Michel Foucault en torno a la monstruosidad vertidas en Los anormales (2001) y La vida de los hombres infames (1990).
} 
Nuestro interés es detenernos en esas figuras monstruosas para analizar precisamente ese enclave que cabalga entre lo imposible y lo prohibido, que venimos soslayando; figuras monstruosas que evocan la idea de mezcla, de confusión de reinos y tópoi que la excepcionalidad de la monstruosidad implica.

Citamos Foucault al respecto: “Así, se dirá que es monstruo el ser en quien leemos la mezcla de dos reinos, porque, por una parte, cuando podemos leer, en un único y mismo individuo, la presencia del animal y de la especie humana, y buscamos la causa, ¿a qué se nos remite? A una infracción del derecho humano y el derecho divino, es decir, a la fornicación, en los progenitores, entre un individuo de la especie humana y un animal. Ya que hubo relación sexual entre un hombre y un animal, o una mujer y un animal, va a aparecer el monstruo, donde se mezclan los dos reinos". 4

Las figuras monstruosas acompañan el horizonte fantasmagórico; es más, lo constituyen desde su extrañeza radical, desde su registro amenazante y desde su elocuencia trágica. El monstruo es esa figura del límite, del borde, del margen.

En el corazón de esta experiencia, la presencia de lo monstruoso cobra la forma límite de la alteridad más absoluta. El monstruo es lo otro del hombre. El monstruo es la forma más rotunda de la desviación. El monstruo es lo desterritorializado por excelencia.

El monstruo es aquello que no conserva la forma, precisamente porque la forma es aquello que hace ser a un determinado ser, lo individualiza, lo territorializa y, sobre todo, permite su clasificación. En el monstruo hay una forma en fuga, inapropiable, inasible e inclasificable.

El dispositivo de clasificación permite siempre el control-fijación de aquello clasificado. Dona un espacio definido, un lógos que recoge la clasificación y una posibilidad de maniobra sobre lo clasificado de carácter previsible, pautado y programado. El monstruo escapa a esta posibilidad de control, de clasificación, de maniobra y de discurso. Es propiamente lo inasible, aquello que no se puede capturar desde las herramientas corrientes.

La alteración de las formas rompe con la cadena regular de las asignaciones discursivas y explicativas.

\section{El trabajo de la arqueología}

\footnotetext{
${ }^{4}$ Cf. Foucault, M. Los anormales. Buenos Aires: F.C.E., 2001, p. 69.
} 
Como anticipamos, el intento del presente trabajo es efectuar una excavación arqueológica de las primeras capas-representaciones de lo monstruoso en el marco de un horizonte que aún no ha encontrado su lógos epistémico. De allí que se nos imponga viajar a la Grecia Arcaica y encontrar el suelo mítico como Grund propicio de una cierta construcción.

Es el momento de Gorgo.

Es el momento cartográfico por excelencia. Los griegos deberán fundar el territorio de lo Mismo y para ello deberán incluir, como espejo invertido, las formas de lo otro, hasta fundar inclusive el paradigma de la Otredad en su forma más cruda y brutal.

No hay forma de conjurar el peligro de la alteridad sin recurrir a ella misma para territorializarla y desde su tópos, convenientemente asignado, acotar el territorio de lo Mismo. Se trata siempre de un movimiento donde lo Mismo integra lo Otro, produciendo loa acogida de ese Otro en el seno de lo Mismo, con todas las implicancias que supone dicha heterogeneidad. El concepto de cultura, en tanto éthos de instalación en el mundo, supone ese juego complejo de integración de las distintas formas de alteridad, desde las más familiares a la alteridad absoluta, de los otros intraculturales a esos otros que parecen pertenecer a otros tópoi culturales. Es la apuesta de la Mismidad para preservar su identidad y asegurar su permanencia como modo cultural y civilizado. El otro resultado el espejo donde se invierte el paradigma consolidado. Según Vernant, "la distancia permite comprender con claridad que todo grupo humano, toda sociedad, toda cultura, por más que se conciba a sí misma como la civilización - cuya identidad se debe preservar y cuya permanencia es necesario asegurar contra las interrupciones de lo foráneo y las presiones internas-, se enfrenta al problema de la alteridad en gran variedad de formas". 5 Se trata de un problema político: asegurar las fronteras de lo mismo, conjurando los avances de lo otro. Se trata de la tarea cultural de asignarle un lugar controlable para que los elementos propios de lo otro no usurpen el lugar que no les corresponde, so pena de poner en peligro el núcleo de preservación e identidad de lo Mismo. Es una política de gendarmería que acota las territorialidades, sabiendo que el Otro no puede ser aniquilado, sino integrado, bajo parámetros de control, al campo de la cultura.

\footnotetext{
${ }^{5}$ Cf. Vernant, op. cit., 1983, p. 37.
} 
Los griegos parecen haber tenido esa capacidad de integrar en su seno lo que le es foráneo, de asimilar al otro sin caer en el "salvajismo". 6

Si pensamos la cultura griega como un complejo universo e relaciones múltiples, podemos decir que los griegos construyeron su Mismidad a partir del Otro y con el Otro, como modo de autodefinición e instalación identitaria.

Se trata de pensar la cultura como un tópos múltiple, capaz de albergar diferentes habitantes, con tal que cada cual está perfectamente territorializado en sus marcas específicas. El problema no es exactamente la presencia del Otro, necesaria y esperable, sino su irrupción allí donde no se lo espera, ni se tiene las herramientas para conjurar sus efectos.

Ahora bien, ¿Qué es un otro para los griegos? ¿Quiénes encarnan la representación de la alteridad desde sus formas más débiles hasta su imagen más radicalizada? El tema es ver en relación a qué parámetros culturales de pertenencia o no pertenencia un Otro es otro. El bárbaro, la mujer, el esclavo parecen jugar su otredad en relación a un parámetro fuerte de relación especular: el ciudadano griego, varón, libre, portador de derecho y del lógos político como herramienta de consolidación de su pertenencia a la pólis. Es a estos otros a los que nos referimos cuando hablamos de un otro más débil, concepto que en modo alguno se refiere a una relación de fuerzas; el término se juega en el extremo de la imagen vigorosa que representa la alteridad más absoluta: Gorgo es el extremo mismo de la tensión; "ya no el ser humano distinto del griego sino aquello que se manifiesta como radicalmente distinto del ser humano: no el hombre otro sino el Otro del hombre". ${ }^{7}$ Se trata de una fractura ontológica en la consideración del Otro. Gorgo es lo otro del hombre porque representa la más pura heterogeneidad, es su calidad de ser las que está en debate.

Frente a los otros Otros, la posición del griego adulto es lo que determina la consideración de lo foráneo; hay una mirada-instalación que ubica al otro en un lugar inferior, con atribuciones axiológicas que lo instalan en el lugar minusvalorado.

Cuando aparece la Otredad en estado puro la cosa cambia radicalmente; no es ya el juego de las valoraciones lo que determina su alteridad; es su registro de ser lo que lo pone en clave de extrema foraneidad.

Los otros Otros guardan cierta relación con el espacio: los bárbaros están en un espacio territorial y cultural no griego; los esclavos están en otro lugar que no es el del

\footnotetext{
${ }^{6}$ Cf. Vernant, op.cit., 1983 , p. 36.

${ }^{7}$ Cf. Vernant, op. cit., 1983, p. 39.
} 
hombre libre y la mujer está ubicada en un territorio a su medida, sin participar del tópos viril, reservado a la mayor racionalidad. Gorgo no encaja en ningún territorio posible; fractura las asignaciones topológicas, ya que es pura fuerza desterritorializante; es aquello que desde su no lugar, saca al hombre de cualquier lugar posible, precisamente "para precipitarlo al abismo donde reina el horror y la confusión del caos". 8

\section{El tributo iconográfico}

La reproducción artística devuelve una doble imagen de Gorgo: por un lado, la forma de la máscara, gorgoneíon, ya que, como sabemos, es una potencia que porta máscara, elemento que lo emparienta con Dioniso, y, por otro, la imagen del personaje femenino con cara de Gorgona. El primer elemento que sorprende es su frontalidad, marca que discontinúa la familiar representación plástica en el universo de los dioses; experiencia de lo extraño, de lo poco familiar e inédito que habla de una fractura en los cánones habituales de representación. Rostro aterrador que, como si fuera poco el espanto de su mueca, mira de frente, convocando a una mirada que paraliza, congela como congela la alteridad más extrema, sobre todo allí cuando no parece haber lógos para decodificar la experiencia.

Pensemos algunas marcas que evocan la figura de la monstruosidad que problematizamos en el primer apartado del presente trabajo. Gorgo parece compartir con aquellas figuras evocadas el perfil de la desviación, del trastocamiento, de la distorsión, de la desterritorialización de toda forma conservada. Dice Vernant "Cualesquiera que fueran las modalidades de distorsión empleadas, la figura siempre muestra cruzas de lo humano con lo bestial, asociados y mezclados de distintas maneras" ${ }^{9}$ Retorna la mezcla de reinos que fuera la nota dominante del monstruo en su configuración teórico-plástica.

Gorgo devuelve en su figura monstruosa la intersección heterogénea de planos, hombre y bestia, conviviendo en una imagen aterradora que se permite la licencia de mezclar lo que debe guardar sus respectivos territorios ontológicos.

Hay una dimensión que roza el páthos a partir de esta experiencia de lo áltero. ¿Qué significa enfrentar a la Gorgona? ¿Cuál es el sentimiento que su presencia provoca? La experiencia de lo monstruoso genera un abanico de sentimientos que no

\footnotetext{
${ }^{8}$ Cf. Vernant, op. cit., 1983, p. 40.

${ }^{9}$ Cf. Vernant, op. cit., 1983, p. 44.
} 
pueden aprehenderse desde una lectura lineal, sobre todo porque conviven sentimientos como la extrañeza y la fascinación. Semejante nivel de otredad fascina por romper la habitualidad de los esteriotipos conocidos, al tiempo que causa temor y horror. Gorgo devuelve una mueca, no un rostro y causa espanto, al tiempo que genera la angustia de romper las certezas de las imágenes familiares. Se trata de esa angustia existencial que pone al hombre cara a cara con lo que no parece tener lógos, al modo de la presencia de la muerte, como límite extremo de los mortales. Esa experiencia sólo se transita desde alguna representación posible que bordee el territorio de aquello que evoca espanto y horror. En efecto, "Al trastocar los rasgos que componen el rostro humano logra un efecto extraño e inquietante, expresión de algo que oscila entre dos polos: lo aterrador y lo grotesco". ${ }^{10}$ Mueca de horror y terror de quien mira: esa parece ser la ecuación de una relación hombre-divinidad que se juega en los márgenes de lo tolerable.

\section{El legado de la genealogía}

Revisar la teogonía hesiódica nos ubica en la peculiaridad de la familia de Gorgo y contribuye a bordar un tapiz más amplio en el cuadro general de la monstruosidad. No es precisamente la tranquilizadora familia de otras divinidades que parecen portar la luminosidad y la positividad; figuras que se juegan precisamente en el horizonte de lo claro y lumínico.

La pareja primordial la constituyen Ceto y Forcis y las Gorgonas deben buscarse entre sus descendientes. En primer lugar, nacieron las Grayas de bellas mejillas, canosas desde su nacimiento (Teogonía, 271). A veces se las representa como viejas y feas, otras como jóvenes y delgadas. Son llamadas viejas por su pelo, canoso desde el nacimiento. Dato singular que parece devolver cierta distorsión, ya que estamos en presencia de un niño-viejo, de un niño con caracteres no usuales a su esteriotipo. Situación extraordinaria ya que el nacimiento no parece estar vinculado a la cabellera cana: yuxtaposición de registros cronológicos en un mismo ser: viejo y joven en una simultaneidad inusual.

Se trata de Enio, Penfredo y Dino, hijas de Forcis y por ello llamadas las Fórcides. Hesíodo parece desconocer la versión de que poseían un solo ojo y un solo diente que compartían por turno las tres. No hace referencia a ello. Pinta el bello peplo de Penfredo y el azafranado de Enío e inmediatamente presenta a las Gorgonas, "que

\footnotetext{
${ }^{10}$ Cf. Vernant, op. cit., 1983, p. 44.
} 
viven al otro lado del ilustre Océano, en el confín del mundo hacia la noche, donde las Hespérides de aguda voz: Esteno, Euríale y la Medusa desventurada; ésta era mortal y las otras inmortales y exentas de vejez las dos" (Teogonía, 274-278). Las dos primeras habitaban en Occidente, cerca del reino de los Muertos. Su aspecto era espantoso, con serpientes en lugar de cabellos, grandes colmillos, manos de bronce y alas de oro. Occidente es el lugar de las Hespérides, hijas de la Noche y de Eris. Son las que "cuidan las bellas manzanas de oro y los árboles que producen el fruto" (Teogonía, 215-218).

Recuperemos algunas imágenes del relato hesiódico. Pensemos en la otredad topológico-lumínica que representan: "al otro lado", "en el confín del mundo", "hacia la noche"; las expresiones parecen intersectar una territorialidad áltera, un espacio otro, con una metáfora lumínica que evidencia oscuridad. La espacialidad y la luminosidad responden a un mismo núcleo que aúna alteridad y tiniebla. Cierra la descripción la elocuencia de un adjetivo que marca la naturaleza de la Gorgona: la Medusa desventurada, seguramente anticipando su destino final en manos de Perseo, que, por no temerle, puede matarla empleando para ello objetos mágicos, "que le proporcionan Atenea y Hermes: sandalias aladas, casco de Hades, que le hace invisible, hoz de un metal milagroso (diamante), zurrón especial, escudo de bronce de Atenea", ${ }^{11}$ según las referencias de Apolodoro. ${ }^{12}$

Pero, antes de su muerte, pensemos en su unión con Posidón, hijo de Crono y Rea, hermano de Zeus, el de Azulada Cabellera, que con ella se acostó "en un suave prado, entre primaverales flores" (Teogonía, 280). Posidón, "que abarca y sacude la tierra" (Teogonía, 15) es la criatura que se anima a amar a la Medusa. El fruto de la unión, luego de que Perseo le cercenara la cabeza, fueron dos peculiares criaturas, nacidas de la sangre de Medusa: el caballo Pegaso, nacido cerca de los manantiales y de allí su nombre, respondiendo a la raíz pegé, manantial, o bien, al plural pegaí, las aguas de un río, y el enorme Crisaor, el que "tenía en sus manos una espada de oro" (Teogonía, 284), a partir de los nombres chrysós, oro, y áor, espada.

El destino de los nacidos fue bien diferente; mientras el primero ascendió a las mansiones de los Inmortales, donde reside cerca de Zeus, llevándole el trueno y el rayo, el segundo se unió con Calírroe, de bellas corrientes, hija de Océano, que da también el nombre a la fuente de donde se extraía el agua para el baño ritual que una novia debía tomar antes de su boda.

${ }^{11}$ Cf. Hesíodo. Teogonía; Trabajos y Días; Escudo; Certamen. Madrid: Alianza, 1996, p. 174.

${ }^{12} \mathrm{Cf}$. Apolodoro, Bib. II 4, 2 ss. 
De la unión de Crisaor y Calírroe nace un monstruo de tres cuerpos yuxtapuestos, Gerión. En efecto, la descendencia de esta peculiar familia que iniciaran Ceto y Forcis se degrada hacia formas cada vez más animalizadas, rozando la monstruosidad. Heracles, hijo de Zeus y Alcmena, nacido en Tebas, es el encargado de darle muerte. Conocemos las virtudes de este héroe encargado de limpiar lo monstruoso que azota con su extrañeza al mundo de los hombres. Su tarea es limpiar el cosmos de aquellos elementos que atentan contra su mismísimo orden (kósmos) y legalidad. Hesíodo relata el episodio purificador en estos términos: "A éste lo mató el fornido Heracles por sus bueyes de marcha basculante en Eritea rodeada de corrientes. Fue aquel día en que arrastró los bueyes de ancha frente hasta la sagrada Tirinto, atravesando la corriente del Océano [después de matar a Orto y al boyero Euritión en su sombrío establo, al otro lado del ilustre Océano]" (Teogonía, 290-295).

En los juegos de la degradación hacia la animalización, una nueva criatura, Equidna, se suma a la descendencia de Ceto y Forcis, hijos de Ponto y Gea: "Tuvo Medusa en una cóncava gruta: la divina y astuta Equidna, mitad ninfa de ojos vivos y hermosas mejillas, mitad en cambio monstruosa y terrible serpiente, enorme, jaspeada y sanguinaria, 'bajo las entrañas' de la venerable tierras. Allí habita una caverna en las profundidades, bajo una oronda roca, 'lejos de los inmortales dioses y de los humanos mortales"” (Teogonía, 296- 304).

Pura mezcla de reinos, mitad mujer y mitad serpiente. Figura paradojal que encierra una cara diáfana con "sus ojos vivos y hermosas mejillas" y una cara tenebrosa de terrible serpiente, "enorme, jaspeada y sanguinaria". Juego de tensiones propio de la lógica de la ambigüedad, donde un mismo ser encierra sin contradicción un juego de oposiciones que lo constituyen intrínsecamente. Ninfa y serpiente, vivaz y hermosa, pero jaspeada y sanguinaria, el monstruo abraza en su ser la dualidad de tópoi, los rasgos de su cara humana y las marcas de su rostro animal.

La metáfora topológica retorna a partir de la solidaridad entre monstruosidad y espacio subterráneo. Sabemos cuál es el tópos habitual de las formas de la otredad, frente al tópos abierto y lumínico de las formas de la mismidad. Espacios oscuros y clausurados frente a tópoi abiertos y luminosos parecen marcar la tensión entre lo grato a la vista y lo que causa horror y espanto. Las culturas suelen ser cuidadosas en la asignación de los lugares que binarizan lo tolerable de lo intolerable. Así la espacializa Hesíodo: "Allí habita una caverna en las profundidades, bajo una oronda roca, lejos de 
los inmortales dioses y de los humanos mortales; allí entonces le dieron como parte los dioses habitar ilustres mansiones [y fue retenida en el país de los Árimos, bajo la tierra, la funesta Equidna ninfa inmortal y exenta de vejez, por todos los siglos]" (Teogonía, 301-305).

Criatura desterritorializada que no parece tener espacio ni entre los mortales ni entre los inmortales; de allí su lejanía, su radical distancia ontológica, que la ubica en otro registro de ser, también desterritorializado. Ciertas expresiones locativas aluden a su propia posición onto-espacial: "caverna en las profundidades", "bajo una oronda roca", "lejos de", "bajo la tierra", parecen indicar la intersección de las metáforas que venimos persiguiendo: la metáfora topológica vinculada a los espacios que están debajo de la tierra y la solidaria metáfora lumínica vinculada a la oscuridad que lo subterráneo evoca. Superficie y subsuelo, luz y sombra, visibilidad e invisibilidad son las territorialidades y las luminosidades que se juegan permanentemente.

Más allá de sus características parece que hay un novio para cada criatura. El elegido es Tifón y, por supuesto, asistiremos a un ser isomorfo en su registro ontoespacial. "Con ella cuentan que el terrible, violento y malvado Tifón tuvo contacto amoroso, con la joven de vivos ojos" (Teogonía, 307-308). Tifón es hijo de Gea y Tártaro, ya que "luego que Zeus expulsó del cielo a los Titanes, la monstruosa Gea concibió a su hijo más joven, Tifón, en abrazo amoroso con Tártaro preparado por la dorada Afrodita" (Teogonía, 820-825). Terrible, violento, malvado, enorme, jaspeada, sanguinaria, tenebrosa, son algunos de los adjetivos que venimos rastreando de la lectura hesiódica como forma de territorializar las características de lo monstruoso en tanto forma de la otredad. Más allá de su contacto amoroso con Equidna, lo que habla de una unión sexuada, Tifón constituye el último gran adversario de Zeus, el padre de hombres y dioses en su gesta cosmificante. Sabemos la resolución última del conflicto bélico, feliz en su desenlace para mortales e inmortales, por cuanto un Zeus poderoso, dotado del trueno, su fuerza y el rayo, sus armas invencibles, termina envolviendo en llamas las monstruosas cabezas del hijo de Gea, hasta que fulminado por la acción benefactora del dios "cayó entre los oscuros e inaccesibles barrancos de la montaña" (Teogonía, 860-861). El fin refuerzas las metáforas. Tifón cae a la oscuridad, a la inaccesibilidad de un tópos áltero, destinado a las criaturas monstruosas; allí donde no llega la luz del sol, ni la mirada de los hombres, más allá de todo y por debajo de todo. Ese es el no lugar de lo otro. 
Retornemos a la unión, concebida en abrazo amoroso. Tifón y Equidna completan el dispositivo de animalización iniciado, ya que su descendencia se juega enteramente en el tópos animal. "Y preñada, dio a luz feroces hijos: primero parió al perro Orto para Gerión. En segundo lugar tuvo un prodigioso hijo, indecible, el sanguinario Cerbero, perro de broncíneo ladrido de Hades, de cincuenta cabezas, despiadado y feroz. En tercer lugar engendró a la perversa Hidra de Lerna, a la que alimentó Hera, diosa de blancos brazos, irritada terriblemente con el fornido Heracles" (Teogonía, 860-861). Singular descendencia territorializada en ese enclave que reúne animalidad con monstruosidad. Los adjetivos enfatizan el catálogo de caracteres negativos que hemos apuntado: feroz, prodigioso, indecible, sanguinario, despiadado y perversa. El catálogo es abundante y siempre inclina la interpretación hacia las características que constituyen ontológicamente al otro. Dos quisiéramos remarcar: prodigioso e indecible. El prodigio, téra, es aquello del orden de lo sobrenatural, de lo extra-ordinario, que se inscribe en un registro precisamente áltero porque rompe con la familiaridad de lo conocido y cotidiano. Es lo xénos por excelencia, en tanto raro, inédito, poco familiar. El segundo sostiene el páthos ante lo monstruoso: no nombrar, no pronunciar el nombre como forma de conjurar el peligro que el mismo arrastra. Donar un nombre es donar identidad, presencia; lo que no puede ni debe decirse, lo indecible, es aquello que no tiene entidad. Es la ilusión de la ausencia de aquello que no entra en el registro de decibilidad. Si no se lo nombra, no tiene tópos; sólo el del horror, que no es poco, claro está.

Hay un rasgo propio de la monstruosidad que aparece en estas criaturas: la desmesura, la hýbris que caracteriza al monstruo. El monstruo es un ser transido por el exceso, la desmesura, en tanto ruptura de la medida. Repasemos sus anatomías. Gerión tiene tres cuerpos yuxtapuestos, Cerbero posee cincuenta cabezas, Tifón, cien cabezas de serpiente que salen de sus hombros y la Quimera ostenta tres cabezas. Cualquier medida estalla en un número desmesurado, que rompe cualquier orden. Aparece, pues, la a-cosmicidad que atraviesa al monstruo.

La descendencia continúa el mismo registro que se viene consolidando en el tópos de lo monstruoso. La Hidra, aniquilada por Heracles, "parió a la terrible, enorme, ágil y violenta Quimera, que exhala indómito fuego. Tres eran sus cabezas: una de león de encendidos ojos, otra de cabra y la tercera de serpiente, de violento dragón" (Teogonía, 320-323). 


\section{La espacialidad en Teogonía. Las marcas del linaje}

A continuación nos proponemos abordar la noción de espacio en el relato hesiódico a la luz del marco precedente. Nos centraremos en él, sabiendo que es un tópico entre otros apto para ensayar el esquema propuesto.

Una primera aproximación etimológica al término topos, ya que, el trabajo se jugará en lo que llamaremos una metáfora topológica o espacial. Las acepciones devuelven una serie de niveles aparentemente heterogéneos: lugar, sitio, puesto, país, territorio, localidad, distrito, región, espacio, condición, categoría, ocasión, posibilidad, oportunidad. Si bien la mayoría del corpus se juega en la línea de la metáfora espacial, hay algo que parece solidarizar espacio y categoría. La línea de la lectura transita exactamente en esa solidaridad: cómo la espacialidad devuelve la condición, la categoría.

El inicio del canto despliega las primeras imágenes claras y positivas de una geografía asociada a figuras del mismo corte estructural: las musas y su padre, Zeus. "Comencemos nuestro canto por las Musas Heliconíadas, que habitan la 'montaña' grande y divina del Helicón”. Con sus pies delicados danzan en torno a una fuente de violáceos reflejos y al "altar" del muy poderoso Cronión. Después de lavar su piel suave en las aguas del Permeso, en la fuente del Caballo o en el "divino Olmeo", forman bellos y deliciosos coros en la "cumbre del Helicón” y se cimbrean vivamente "sobre sus pies" (Teogonía, 1-9). Al pie del monte Helicón, en el valle de las Musas, se halla Pieria, lugar de nacimiento de las bienhabladas hijas de Zeus, quienes nacieran de su unión con Mnemosýne, la señora de las colinas de Eleutera. Se trata de una cadena montañosa de Beocia, a lo largo del golfo de Corinto y representa su cima más alta. Dos nuevas referencias espaciales completan el cuadro: el Permeso, río de Beocia, que nace en el monte Helicón y que se junta con el Olmeo, otro pequeño río de la misma región. Finalmente la citada fuente en la cima del Helicón, la "fuente del caballo", presumiblemente nacida de una coz de caballo Pegaso. ${ }^{13}$ El espacio empieza a delinear una región superior, elevada, que reconoce una montaña dominante, el Helicón, que retorna en el verso 24 como divino, precisamente cuando Hesíodo da cuenta de su iniciación poética, mientras apacentaba sus ovejas, "al pie del divino Helicón”.

\footnotetext{
${ }^{13}$ Seguiremos en la especificidad de las referencias geográficas el magnífico aporte al respecto de la doctora Lucía Liñares en Hesíodo. Teogonía; Trabajos y Días. Edición bilingüe, con introducción, traducción y notas de L. Liñares. Buenos Aires: Losada, 2006.
} 
Para comprender este plano espacial superior, un "arriba" que va a tensionarse con un "abajo" como plano subterráneo, debemos situarnos en Gea, la sede siempre segura y firme, el suelo del mundo como afirma Vernant. Tal como advierte Hesíodo: "En primer lugar existió el Caos. Después Gea la de amplio pecho, 'sede siempre segura' de todos los Inmortales que habitan la 'nevada cumbre del Olimpo'. [En el ‘fondo de la tierra' de anchos caminos existió el tenebroso Tártaro.]” (Teogonía, 116120).

Estos versos marcan precisamente el marco de la espacialidad que venimos rastreando. La nevada cumbre del Olimpo constituye la extensión-prolongación de Tierra hacia el plano superior. Gea se prolonga en las montañas, abriendo hacia arriba el plano visible. Pero Gea también se extiende hacia el plano contrario, hacia abajo, hacia el espacio otro, hacia el tópos subterráneo e invisible en forma de Tártaro, mundo abismal, que devuelve la cara de Gea hacia lo inferior.

La evocación homérica es también expresa en torno a la vastedad de Tierra; basta remitirnos a las palabras de Hera en el canto XIV de Ilíada, respondiendo a Afrodita: "Pues voy a los confines de la feraz tierra a ver a Océano, progenie de los dioses, y a la madre Tetis, que en sus moradas me criaron y me mimaron, acogiéndome de manos de Rea cuando Zeus, de ancha voz, instaló a Crono bajo la tierra y bajo el proceloso mar". 14

La vastedad de Tierra también queda atestiguada en la imagen que Hesíodo elige para dar cuenta de la distancia que separa al Cielo de la Tierra, idéntica a la distancia que separa a ésta del tenebroso Tártaro, sobre el cual se alzan las raíces de la Tierra y el mar inmenso.

Gea representa el suelo del mundo que, a su vez, se extiende hacia arriba, en forma de montañas y desciende hacia lo subterráneo, siendo, en última instancia, el mismo y propio Caos el que se halla por debajo de Gea, reactualizando la misma tenebrosa negritud, ahora subterránea.

Tierra aparece pues como una figura dual, ambigua. Ella misma es nítida y visible, así como todo lo que sobre ella se instala, pero también es oscura en sus profundidades y se asemeja a Caos. Fondo paradojal que constituye por otra parte, una constante en el marco de la divinidad.

${ }^{14}$ Cf. Homero, Ilíada XIV, v. 200-204. 
Recordemos lo que hemos dicho del Tártaro: morada de los dioses vencidos y de los muertos. Un primer espacio se recorta para albergar la otredad, aquellos seres emparentados con la derrota o la muerte que aparecerán a su turno en la presente propuesta. Como contrapunto de esta tipo de "mansiones subterráneas" se alzan las “mansiones olímpicas” como tópos diáfano de los dioses.

\section{Conclusiones}

El proyecto de la presente comunicación consistió en efectuar una lectura de la relación entre monstruosidad y espacialidad en el marco de la Teogonía hesiódica. No obstante, no se trata de un intento lineal de abordar dicha relación inscrita en el relato mítico, sino, de un intento más ambicioso de pensarla a la luz de un proyecto de lectura que ponga de relieve la existencia de dos linajes al interior del mito; lectura que involucra tanto a la "monstruosidad" como a la "especialidad" como dos de las tantas variables que pueden quedar subsumidas a la luz del marco interpretativo.

Existen, en la mitología griega en particular, y en la cultura griega en general, dos campos simbólicos que permiten clasificar y significar a la realidad, expresados en la figura mitológica del linaje: lo nocturno y negativo, y lo luminoso y positivo.

Para ello nos instalamos frente al universo mítico para ver en él un modo de discurso tendiente a comprender lo real; se trata, en última instancia de un posicionamiento frente a un tipo de lógos que no siempre tuvo el estatuto de "lógos explicativo". La posibilidad de experimentar una lectura más compleja sobre el discurso mítico, como el relevamiento de los linajes anunciados, supone superar lecturas que ponen al mito en el lugar de un tipo de discurso que no ha alcanzado el registro del pensamiento racional, como esteriotipo de todo modelo de pensamiento.

Desde este andamiaje, seguimos entonces el modelo interpretativo de la Escuela de Antropología Histórica de París, iniciada por Louis Gernet, que se nutre de la renovación del marxismo de la Escuela de los Anales, fundada por Bloch y Febvre, y del estructuralismo de Lévi-Strauss. Por un lado, resignificar las relaciones entre la materialidad de la vida social y las representaciones de la ideología de una manera no determinista o no economicista, permitió entender a la mitología como una variable más dentro de la configuración de las sociedades. La base material dialogaba con la espesura mítica, oxigenando las lecturas cifradas en lo económico como única variable de análisis. A su vez, el estructuralismo de Lévi-Strauss, que dominó gran parte del siglo 
XX, puso definitiva y claramente a la mitología a la par de cualquier otra forma de pensamiento, retirándola de la tiranía de las metáforas aludidas. El mundo devino más racional, más claro, desde que el estructuralismo sacó a la mitología de su lugar de pensamiento imperfecto y defectuoso y le devolvió su complejidad estructural, como la de cualquier otro esquema de pensamiento.

Con respecto a los antecedentes puntuales del tema de la presente comunicación, es necesario ubicarse en los estudios de la Escuela de Antropología Histórica de París, por razones que se desprenden de lo anterior. Sólo cuando la mitología devino pensamiento racional fue posible estudiar las figuras mitológicas más oscuras y monstruosas como expresiones de un universo de sentido. Los libros de Jean Pierre Vernant y de Marcel Detienne, así como los de Nicole Loraux, para el caso de las figuras negativas femeninas, o de Ana Iriarte, son fundamentales para comprender el lugar que ocupa la tensión positivo-negativo, claro-oscuro en el concierto de las figuras que sostienen la cultura griega. El conjunto de estos helenistas realizan un análisis estructuralista de gran parte de las divinidades griegas, entendiéndolas dentro del esquema propio de dicha teoría en donde todos los elementos entran en clasificaciones más o menos rígidas.

Nos propusimos desplazar la mirada hacia el campo de la tensión MismidadOtredad, para abordar ciertas figuras o espacios del pensamiento mítico que constituyen la cara de lo Otro en el mundo arcaico, resultando el discurso mítico el espejo mismo de la tensión.

A medida que avanzamos en la temática, descubrimos que el campo luminoso en materia mítica constituye la geografía donde convergen diversas líneas y que, además, constituye el tópos fundacional para tender puentes hacia la filosofía clásica, a nuestro entender, de notorio parentesco estructural con el discurso del mito en lo que se refiere a la conservación de esteriotipos que portan la claridad o la tenebrosidad en materia político-moral. Es en este marco donde la tensión aludida cobra especial significación. Tanto la constitución del sujeto moral como la constitución del sujeto político en la Grecia clásica parecen responder a ciertos antecedentes míticos que deben ser leídos en el marco de la tensión aludida (luminosidad-positividad, oscuridadnegatividad). Ciertas figuras, como Apolo, Zeus, y otros habitantes de la arquitectura olímpica, parecen encarnar los valores de lo Mismo, de lo Positivo, de lo Luminoso, de la Soberanía. 
Pero, sabemos la lección antropológica, esta Mismidad-Luminosidad, siempre se autoafirma en un movimiento especular registrándose como imagen invertida en el topos de lo Otro-Oscuridad. En ese marco, figuras como las que a partir de Noche, representan su linaje nocturno, y otras divinidades de sesgo negativizado parecen representar el otro polo de la tensión; de allí nuestra inquietud de problematizar las figuras de lo Otro-Oscuro, como contrapartida de las figuras de lo Mismo-Luminoso.

Luego de indagar las figuras monstruosas como plasmación del linaje nocturno, incluimos la "categoría del espacio" como núcleo de indagación; el espacio se erige como figura de apropiación para desplegar el marco teórico propuesto, como superficie sobre la que podemos hacer pie para avanzar en el proyecto planteado.

Si pensamos en el vasto huerto de las figuras monstruosas o en la abundante cartografía de ambos signos, presentes en Homero y en Hesíodo, emparentadas con el linaje nocturno y con el concepto de hýbris, la noción de medida y de límite, familiar al pensamiento ético-filosófico, parece tener su propia prehistoria, donde el topos mítico ofrece huellas singulares.

En este marco, ¿Qué relaciones hay entre la Oscuridad-negatividad y la falta de medida? ¿En qué sentido el linaje negativo constituye un cierto modelo de hýbris, y con ello un contramodelo de la noción de medida, solidaria a la idea de sophrosýne y del linaje positivo? ¿Cómo juega la variable espacial al interior de la lógica de linajes?

¿Cuál es el páthos que supone la presencia de lo Otro como linaje negativo y cuál su espacialización, tanto ontológica como material? ¿En qué sentido hay algo del orden del horror en esas figuras-espacios nocturnos?

La identificación y la re-construcción de estos dos linajes permite realizar una nueva clasificación del conjunto del edificio de la mitología griega. Los dos linajes no sólo dan cuenta de una genealogía explícitamente narrada en la mitología, sino que definen dos tópos simbólicos. De esta forma, la reconstrucción de cada uno de estos dos tópoi simbólicos permite identificar y reconocer, de manera original, dos valoraciones, dos ideales presentes en la cultura griega. No se trata, pues, simplemente, de una descripción de dioses o lugares, sino de la definición del eídos positivo y del eídos negativo de los griegos. La mitología sería la primera en recortar estos dos tópoi y poblarlos de una multiplicidad de potencias y figuras divinas que realizan una primera definición de esas dos valoraciones opuestas de la vida espiritual helena. 


\section{Referencias}

BERMEJO BARRERA, J. C.; GONZÁLEZ GARCÍA, F. J.; REBOREDO MORILLO, S. Los orígenes de la mitología griega. Madrid: Akal, 1996.

COlOMBANI, M. C. Hesíodo. Una introducción crítica. Buenos Aires: Santiago Arcos, 2005. . Foucault y lo político. Buenos Aires: Prometeo, 2009.

COMFORD, F. M. From religion to philosophy. New York: Harper Torchbook, 1957.

DETIENNE, M. Los maestros de verdad en la Grecia arcaica. Madrid: Taurus, 1986.

DODDS, E. R. The Greeks and the irrational. Berkeley: University of California Press, 1964.

FOUCAULT, M. La vida de los hombres infames. Madrid: La Piqueta, 1990. .Los anormales. Buenos Aires: F.C.E., 2001.

. La arqueología del saber. México: Siglo XXI, 1984. . Las palabras y las cosas. México: Siglo XXI, 1968.

GARRETA, M.; BELLELI, C. La trama cultural. Textos de antropología. Buenos Aires: Caligraf, 1999.

GERNET, L. Antropología de la Grecia antigua. Madrid: Taurus, 1981.

HESÍODO. Teogonía; Trabajos y Días. Edición bilingüe con introducción, traducción y notas de L. Liñares. Losada: Buenos Aires, 2005.

Agostini, 1997.

Teogonía; Trabajos y días; Escudo. Barcelona: Editorial Planeta De . Teogonía; Trabajos y Días; Escudo; Certamen. Madrid: Alianza, 1996. 


\section{nuntius antiquus}

HOMERO. Ilíada. Madrid: Gredos, 2000.

NILSSON, M. P. Historia de la religiosidad griega. Madrid: Gredos, 1969.

VERNANT, J.-P. La muerte en los ojos. Gedisa, 1983.

. Mito y pensamiento en la Grecia Antigua. Barcelona: Ariel, 2001.

Mito y religión en la Grecia antigua Barcelona: Ariel, 2001.

F.C.E., 2000.

Érase una vez...El universo, los dioses, los hombres. Buenos Aires:

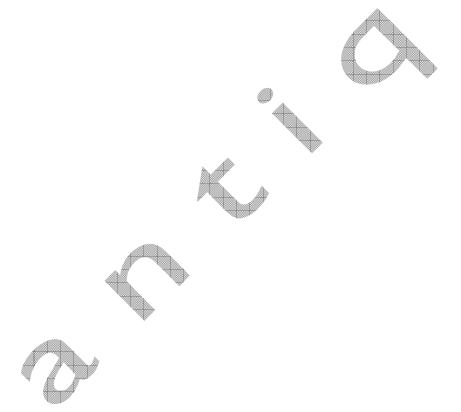

